\title{
Diagnóstico do uso da madeira como material de construção no município de Mossoró-RN/Brasil
}

\author{
Diagnosis of the use of wood as construction \\ material in the city of Mossoró-RN/Brazil
}

Julio Cesar de Paiva Filho ${ }^{1}$, Laury Araujo Almeida ${ }^{1}$, Vinicius Gomes de Castro ${ }^{1}$, Marco Antonio Diodato ${ }^{1}$

\begin{abstract}
${ }^{1}$ Universidade Federal Rural do Semi-Árido - UFERSA. CEP: 59.625-900. Mossoró, RN, Brasil. e-mail: julio_cesar_673@hotmail.com, laury_araujo@yahoo.com.br, vinicius.castro@ufersa.edu.br, diodato@ufersa.edu.br
\end{abstract}

\section{RESUMO}

A madeira como material de construção sempre esteve presente no desenvolvimento da sociedade. É um material que se encontra praticamente em todas as etapas da obra e a construção civil é um dos setores que mais consome esse recurso. Em Mossoró-RN, a construção civil é um importante setor da economia em crescimento, acarretando um intenso consumo de madeira. É possível evidenciar o crescimento urbano da cidade ao se passear pelos principais bairros em desenvolvimento, que são verdadeiros canteiros de obra. Esse trabalho teve como objetivo realizar uma avaliação sobre os principais usos da madeira na construção civil da cidade de Mossoró-RN, as principais espécies vegetais utilizadas e o destino final dos rejeitos gerados. As informações foram coletadas através de levantamento de dados junto com as empresas que comercializam a madeira e as empresas construtoras da cidade. Foi possível observar que a madeira é mais utilizada como item temporário nas obras do que como material permanente, quando a madeira é usada quase que exclusivamente como material de cobertura e esquadrias. O consumo de madeira na construção civil de Mossoró tem uma preferência pelo uso da espécie tropical Maçaranduba (Manilkara sp), proveniente do Pará, embora algumas madeireiras já comercializarem madeira proveniente de florestas plantadas em Minas Gerais e Paraná. Atualmente os resíduos de madeira da construção são coletados por empresas especializadas. Ainda não há uma consciência sobre o reaproveitamento ou reciclagem desse material dentro das construtoras no município.

Palavras-chave: construção civil; resíduo; comércio de madeira.

\begin{abstract}
Wood as a building material has always been present in the development of society. It is a material that can practically be found during all stages of the construction and the construction industry is one of the sectors that has higher consumption of this feature. In Mossoro-RN, the construction industry is an important sector of the economy, causing an intense wood consumption. It is possible to see the urban growth of the city just walking through the main neighborhoods in development, which are real construction sites. This research aims to evaluate the main uses of wood by the civil construction of the city of Mossoro-RN, the main wood species used and the final destination that is given to the waste generated by its use. The information was collected through survey data with companies that sell wood and construction companies in the city. It was observed that the wood is used more as a temporary item than a permanent item in the construction, where it is applied almost exclusively as material for roofing and wood frames. The wood consumption for construction in Mossoró has a preference to the use of Maçaranduba wood (Manilkara sp), a tropical wood originating from the Pará state, however some wood shops had already start to negotiated wood from planted forests from Minas Gerais and Paraná states. Nowadays, the wood waste is collected by specialized companies. Still, there isn't an awareness about recycling and reuse of this kind of material, especially among the construction companies in Mossoró.
\end{abstract}

Keywords: construction; wood waste; wood commerce. 


\section{INTRODUÇÃO}

A madeira como um material de construção sempre foi utilizada pelo homem desde épocas pré-históricas. Até o século XX, as mais importantes obras de engenharia eram construídas com pedra ou madeira, combinando-se frequentemente os dois materiais [1]. Abundante na natureza, a madeira é um recurso insubstituível. Desde os primórdios da civilização, ela sempre desempenhou papel decisivo em todos os aspectos da vida. Através da construção de casas, silos, estradas, pontes, teatros, templos e barragens, a humanidade desde a antiguidade vem moldando a natureza de forma a desenvolver sua capacidade em edificar [1].

No Brasil, a madeira é empregada para diversos fins, tais como, em construções de igrejas, residências, depósitos em geral, cimbramentos, pontes, passarelas, linhas de transmissão de energia elétrica, na indústria moveleira, construções rurais e, especialmente, em edificações, em ambientes altamente corrosivos, como à beira-mar, nas indústrias químicas, curtumes, etc [3]. A madeira é um produto presente em quase todas as etapas das obras de construção civil no Brasil. Seja em formas, estruturas, escoramentos, esquadrias, pisos, forros, revestimentos até a mobília final, o uso da madeira ainda é indispensável para muitos arquitetos e engenheiros, por ser um diferencial de beleza e sofisticação [2].

Porém, a madeira como material de construção ainda apresenta pouca aceitação no Brasil, não somente por questões técnicas, mas simbólicas, isto é, devido às associações da casa de madeira como se fosse de baixa qualidade ou de baixa durabilidade, sendo este um dos principais empecilhos ao seu emprego [6]. O preconceito em relação ao emprego da madeira se deve ao desconhecimento do material, à falta de projetos específicos e bem elaborados e devido a questão cultural. As construções em madeira geralmente são idealizadas por carpinteiros que não são preparados para projetar, mas apenas para executar. Consequentemente, as construções de madeira são vulneráveis aos mais diversos tipos de problemas, o que gera uma mentalidade equivocada sobre esse material [3].

Os engenheiros brasileiros, em sua grande maioria, não recebem uma capacitação adequada sobre o uso da madeira. Devido a essa falta de capacitação, há uma fuga da elaboração de projetos de estruturas de madeira ou, quando há um projeto, não é dimensionado corretamente, ocasionando um comprometimento da estrutura. Assim, é muito comum ver estruturas de madeira apresentando flechas excessivas, com empenamentos, torções, instabilidades, etc [3].

Nos dias atuais, a engenharia de madeira está se tornando muito comum em países que tem a cultura de construções em madeira como os Estados Unidos, Canadá e Noruega. Já há no Brasil cursos específicos de engenharia voltados exclusivamente para o uso e exploração desse recurso. Mas em cursos mais tradicionais, como engenharia civil e arquitetura, são oferecidos em seus currículos carga horária de apenas um período ao estudo da estrutura de madeira, sendo raros os cursos livres oferecidos e escassa a literatura especializada existente sobre $o$ assunto [2].

No município de Mossoró-RN a madeira na construção civil é amplamente utilizada nas diversas etapas da obra. É possível observar ao passar ao lado de um canteiro de obras em Mossoró diversas formas de utilização da madeira na construção como em barracos, tapumes, escoramentos, formas, etc. Foi observando esses diversos usos da madeira nos canteiros de obra da cidade e a pouca ou quase inexistente pesquisa sobre o seu uso no município que surgiu a necessidade de realizar esse trabalho. Com isso, o presente estudo teve como objetivo a realização de uma análise sobre o uso da madeira pelo setor da construção civil no município de Mossoró-RN. Essa análise levou em consideração diferentes aspectos como a origem geográfica da madeira, principais espécies comercializadas, de que forma é utilizada a madeira, suas principais vantagens e desvantagens, entre outros.

\section{MATERIAIS E MÉTODOS}

O estudo foi realizado no município de Mossoró, interior do Rio Grande do Norte, na região Nordeste do Brasil. O município está localizado em uma região estratégica entre duas importantes capitais do Nordeste, Fortaleza e Natal, às quais são ligadas pela BR-304. Em 2015 sua população foi estimada pelo IBGE [4] em quase 290 mil habitantes, caracterizando como segundo município mais populoso do estado.

O presente estudo englobou o mercado da construção civil de Mossoró-RN, com a participação de empresas construtoras e o comércio fornecedor de madeira como matéria prima para este mercado. Foram realizados levantamento de dados em quatro madeireiras, que representa $40 \%$ das empresas comerciais do ramo em funcionamento no município de acordo com o levantamento do site Telelist.net, empresa brasileiro da internet especializada em editoras de listas telefônicas, de empresas e catálogos, no mês de junho de 2015.

Baseado no número de madeireiras, quatro empresas do setor da construção civil atuantes no município contribuíram com o estudo. Com base na lista de construtoras associadas ao Sindicato Industrial da Cons- 
trução Civil de Mossoró, o número de empresas amostradas representou 11,4\% do total de empresas associadas.

As empresas (tanto madeireiras quanto construtoras) do levantamento de dados estão distribuídas de forma heterogênea na cidade de Mossoró-RN, tendo em vista que eles estão localizados em bairros diferentes. O levantamento de dados foi realizado durante o período de Julho de 2015 à Outubro de 2015. O objetivo desse levantamento foi obter informações sobre a forma na qual a madeira é utilizada pelo setor da construção civil no município de Mossoró-RN.

\section{RESULTADOS E DISCUSSÃO}

A tabela 1 apresenta as formas em que são utilizadas madeiras pelas empresas construtoras no município.

Tabela 1: De que forma é utilizada a madeira nas construções da empresa.

\begin{tabular}{|c|c|c|c|c|c|}
\hline ITENS CITADOS & $\%$ & E1 & E2 & E3 & E4 \\
\hline \multicolumn{6}{|l|}{ Itens permanentes } \\
\hline Cobertura & 50 & $\mathrm{X}$ & $\mathrm{X}$ & - & - \\
\hline Esquadrias & 25 & $\mathrm{X}$ & - & - & - \\
\hline \multicolumn{6}{|l|}{ Itens temporários } \\
\hline Formas (pilares, sapatas e vigas) & 100 & $\mathrm{X}$ & $\mathrm{X}$ & $\mathrm{X}$ & $\mathrm{X}$ \\
\hline Sarrafo & 75 & - & $\mathrm{X}$ & $\mathrm{X}$ & $\mathrm{X}$ \\
\hline Barracos & 50 & - & - & $\mathrm{X}$ & $\mathrm{X}$ \\
\hline Escoramento & 25 & - & - & - & $\mathrm{X}$ \\
\hline Tapumes & 25 & - & - & - & $\mathrm{X}$ \\
\hline Gastalho & 25 & - & - & - & $\mathrm{X}$ \\
\hline Bancadas & 25 & - & - & $\mathrm{X}$ & - \\
\hline
\end{tabular}

Sendo: E1, E2, E3 e E4, as empresas de construção civil entrevistadas

FONTE: Autoria Própria, (2016).

No que tange os itens permanentes, o estudo revelou que metade das empresas utilizam a madeira para construção de coberturas (telhados) devido ao fato deste tipo de material apresentar boa trabalhabilidade, resistência e aparência estética. A empresa no qual foi constatada a utilização de madeira em esquadrias (portas e janelas) também justificou seu uso pelos mesmos motivos. Porém, diferente da cobertura, existem no mercado bons materiais concorrentes para produção de esquadrias como vidro, alumínio, ligas metálicas e até mesmo plásticos, o que provavelmente refletiu no fato do estudo constatar que apenas uma das empresas usa madeira para este fim específico.

De acordo com Zenid et al [7], forros, pisos e esquadrias foram o terceiro grupo de maior consumo de madeira na construção civil em levantamento realizado no estado de São Paulo no ano de 2001. Porém, a utilização de produtos de madeira para pisos não foi observada em nenhuma empresa. Isso ocorreu provavelmente devido a questão cultural, uma vez que a região nordeste apresenta elevadas temperaturas durante todo o ano, assim o mercado tende a preferir o piso cerâmico, por ser mais frio do que o piso de madeira, e resultar em um maior conforto térmico.

A utilização da madeira nas construções no município de Mossoró-RN, no que diz respeito aos itens temporários, foi observado que é mais comum como formas para concretagem de elementos estruturais (pilares, vigas, sapatas, etc), seguida de sarrafos. A forma foi o item mais notável durante o levantamento, sendo utilizada por $100 \%$ das empresas, devido ao fato do concreto ser o material de construção mais utilizado tanto no Brasil como no mundo, o que gera a necessidade de formas para moldá-lo e a madeira ser um bom material para esse fim.

Também foi constatada a utilização de sarrafo de madeira em $75 \%$ das empresas, por ser uma peça de madeira versátil, ou seja, pode ser utilizada de diferentes formas. Ele pode ter a função de anel estrutural nas formas de vigas e colunas para a construção, dando suporte para que, no momento da concretagem, as formas não se abram. Também pode ser utilizado nos gabaritos como madeira principal ou como suporte para reforçar a estrutura para não haver deslocamentos. Também utilizados no madeiramento para telhados, os sarrafos 
são os substitutos das ripas em telhados mais pesados.

As instalações dos barracos temporários no canteiro de obra é uma prática comum pelas empresas, tendo em vista que esses barracos servem de abrigo para materiais, refeitórios, áreas de convivência, escritórios, entre outros. Em apenas 50\% das empresas foi observada a utilização de barracos construídos com madeira. É comum encontrar empresas que utilizam contêineres ou abrigos de alvenaria.

Os escoramentos de madeira são utilizados devido a seu baixo custo e foi vista em apenas uma empresa. Isso ocorreu provavelmente devido à presença de um forte concorrente no mercado, que são os escoramentos metálicos, que apresentam diversas vantagens em relação ao escoramento de madeira. Embora mais caro, o escoramento metálico é ajustável para diferentes alturas, diferente do de madeira, que uma vez serrada, não voltará a escorar alturas maiores.

A utilização de madeira para tapume foi constatada apenas em uma empresa. Esse elemento construtivo pode ser feito de madeira, metal ou até mesmo de alvenaria. Muitas construtoras utilizam o metal em detrimento da madeira quando a obra é de longo prazo. Quando as empresas utilizam madeira para esse fim a adquirem de baixa qualidade, por ser mais barata, não sendo uma madeira adequada para essa finalidade. Com isso, essa madeira tem pouca durabilidade e é necessário trocá-la com mais frequência se comparada com tapumes metálicos.

Em apenas uma das empresas foi possível observar o uso de madeira para gastalho. Esse elemento é utilizado em conjunto com as formas de concreto, para dar suporte a estrutura na hora da concretagem.

As bancadas de madeira também foram vistas em apenas uma empresa. A madeira utilizada para essa finalidade deve ser uma madeira resistente e, consequentemente, é uma madeira mais cara. Com a existência de outros materiais para bancadas no mercado, como, por exemplo, ligas metálicas, algumas vezes mais barato do que madeiras mais resistentes, muitas construtoras utilizam bancadas de outros materiais.

A tabela 2 apresenta as espécies vegetais das madeiras e os tipos de produtos madeireiros mais utilizadas pelas construtoras.

Tabela 2: Espécies vegetais das madeiras e produtos madeireiros utilizados por empresas da construção civil em Mossoró/RN.

\begin{tabular}{lllllll}
\hline ITENS CITADOS & NOME CIENTÍFICO & $\%$ & E1 & E2 & E3 & E4 \\
\hline MADEIRA MACIÇA & & & & & & \\
Maçaranduba & Manilkara sp. & 75 & $\mathrm{X}$ & - & $\mathrm{X}$ & $\mathrm{X}$ \\
Pinus & Pinus sp & 50 & - & - & $\mathrm{X}$ & $\mathrm{X}$ \\
Mista* & & 50 & - & $\mathrm{X}$ & $\mathrm{X}$ & - \\
Muiracatiara & Astronium lecointei & 25 & $\mathrm{X}$ & - & - & - \\
MADEIRA RECONSTITUÍDA & & & & & & \\
MDF & & 50 & $\mathrm{X}$ & - & - & $\mathrm{X}$ \\
Compensado & & 25 & - & - & - & $\mathrm{X}$ \\
\hline
\end{tabular}

Sendo: *Mista é um termo utilizado para descrever uso de madeiras tropicais sem espécie definida.

FONTE: Autoria Própria, (2016).

Em se tratando das espécies vegetais das madeiras sólidas utilizadas pelas empresas, as espécies mais comuns foram Maçaranduba, Pinus, Muiracatiara e mista. A Maçaranduba, segundo o IPT [5], possui uma massa específica de $1000 \mathrm{~kg} / \mathrm{m}^{3}$, o que a caracteriza como uma madeira de densidade alta. A Muiracatiara possui uma massa específica média de $970 \mathrm{~kg} / \mathrm{m}^{3}$, também caracterizada como uma madeira de densidade alta. Já a Pinus possui uma massa específica considerada baixa, de $480 \mathrm{~kg} / \mathrm{m}^{3}$. Devido à alta densidade, a Maçaranduba e a Muiracatiara possuem alta resistência a organismos xilófagos e a esforços mecânicos.

No comércio local do município, foi relatado haver uma pouca variabilidade de espécies vegetais disponíveis para a venda. Esta falta de opções no comércio e a boa resistência mecânica da madeira de Maçaranduba, provavelmente, justificam a preferência dos consumidores por esse produto para fins estruturais. Já a madeira de Muiracatiara é mais procurada para fabricação de esquadrias por aliar uma boa aparência estética e uma alta densidade.

Quanto aos painéis, os mais comuns foram o MDF e o compensado. A superfície lisa e boa aparência do MDF fazem com que ele possa ser utilizado como matéria-prima para fabricação de esquadrias e outras 
peças que precisam ser torneadas.

Todas as empresas construtoras analisadas na pesquisa fazem reaproveitamento dos resíduos gerados pela utilização da madeira em obra, reutilizando a madeira até que o desgaste da construção inviabilize sua reutilização, pois esse elemento, se não reutilizado, pode encarecer bastante o custo final da obra.

Três das quatro empresas construtoras contratam empresas especializadas para darem o destino final a esses rejeitos. Essas empresas especializadas disponibilizam containers papa-entulho para as construtoras estocarem esses rejeitos. Quando os containers estiverem cheios, a empresa especializada coleta-os e dá o destino adequado a esses rejeitos.

A tabela 3 apresenta os principais produtos de madeira comercializados pelas madeireiras.

Tabela 3: Principais produtos de madeiras comercializados pelas madeireiras.

\begin{tabular}{llllll}
\hline ITENS CITADOS & $\%$ & $\mathrm{M} 1$ & $\mathrm{M} 2$ & $\mathrm{M} 3$ & $\mathrm{M} 4$ \\
\hline Madeiras serradas em geral & 100 & $\mathrm{X}$ & $\mathrm{X}$ & $\mathrm{X}$ & $\mathrm{X}$ \\
Compensados & 50 & $\mathrm{X}$ & - & - & $\mathrm{X}$ \\
Madeirites & 50 & $\mathrm{X}$ & - & - & $\mathrm{X}$ \\
Esquadrias & 50 & - & $\mathrm{X}$ & $\mathrm{X}$ & - \\
\hline
\end{tabular}

Sendo: M1, M2, M3 e M4, as madeireiras entrevistadas.

FONTE: Autoria Própria, (2016).

De acordo com as informações levantadas, todas comercializam madeira serrada em geral (linhas, caibros, ripas, lambris, terças, etc) e algum outro produto. Duas madeireiras, além de madeira serrada, também comercializam compensados e madeirites. As outras duas, comercializam esquadrias além da madeira serrada. A predominância do comércio de madeira serrada provavelmente ocorreu devido ao fato deste material ser utilizado em grande escala para construção de estruturas de telhado na região de Mossoró.

A tabela 4 exemplifica a finalidade e uso dos produtos de madeira comprados pelos clientes.

Tabela 4: Finalidade e uso dos produtos de madeira.

\begin{tabular}{llllll}
\hline ITENS CITADOS & $\%$ & $\mathrm{M} 1$ & $\mathrm{M} 2$ & $\mathrm{M} 3$ & $\mathrm{M} 4$ \\
\hline Madeiramento para telhado & 75 & $\mathrm{X}$ & - & $\mathrm{X}$ & $\mathrm{X}$ \\
Formas para concreto & 50 & $\mathrm{X}$ & - & - & $\mathrm{X}$ \\
Embalagem de transporte & 25 & - & - & - & $\mathrm{X}$ \\
\hline
\end{tabular}

FONTE: Autoria Própria, (2016).

Foi possível observar que a grande parte das madeiras comercializadas foram vendidas para a finalidade de madeiramento de telhado e formas para concreto, o que condiz com os dados obtidos do levantamento das construtoras, que apontou os principais usos da madeira para as mesmas finalidades.

Em conformidade com a tabela 3, que aponta os principais produtos de madeira comercializadas pelas madeireiras, as madeireiras 1 e 4 que comercializam compensados afirmam também a finalidade do seu uso para formas de concreto.

Foi observado que a madeireira 4 vende madeira para confecção de caixotes para transporte. $\mathrm{O}$ fato de apenas essa madeireira apontar este uso final para seu produto provavelmente se dá ao fato dela ser a única empresa que atende a pedidos especiais de dimensões sob encomenda. Para isso, a madeireira possui uma serra fita e uma serra circular a disposição para este tipo de adaptação e isso faz com que clientes a procurem quando necessitam de material para usos tão específicos quanto a produção de caixotes.

A tabela 5 ilustra as espécies vegetais comercializadas pelas madeireiras.

Tabela 5: Espécies vegetais comercializadas pelas madeireiras.

\begin{tabular}{lllllll}
\hline ITENS CITADOS & NOME CIENTÍFICO & $\%$ & M1 & M2 & M3 & M4 \\
\hline Maçaranduba & (Manilkara spp.) & 100 & X & X & X & X
\end{tabular}




\begin{tabular}{|c|c|c|c|c|c|}
\hline Andiroba & (Carapa guianensis) & 75 & $\mathrm{X}$ & $\mathrm{X}$ & $\mathrm{X}$ \\
\hline Muiracatiara & (Astronium lecointei) & 50 & $\mathrm{X}$ & - & $\mathrm{X}$ \\
\hline Guajará & (Chrysophyllum excelsum) & 50 & $\mathrm{X}$ & $\mathrm{X}$ & - \\
\hline Pinus & (Pinus spp.) & 50 & $\mathrm{X}$ & - & - \\
\hline Eucalipto & (Eucalyptus spp.) & 50 & $\mathrm{X}$ & - & - \\
\hline Mistas* & & 50 & - & - & $X$ \\
\hline Louro & (Ocotea spp.) & 25 & - & - & $\mathrm{X}$ \\
\hline
\end{tabular}

Sendo: M1, M2, M3 e M4, as madeireiras entrevistadas e * mista é um termo utilizado para descrever uso de madeiras tropicais sem espécie definida.

FONTE: Autoria Própria, (2016).

Quanto as espécies vegetais das madeiras comercializadas, a espécie Maçaranduba foi a única madeira comercializada por todas as empresas, tendo em vista uma grande aceitação e preferência dos clientes por essa espécie, já que ela oferece boa resistência tanto mecânica (esforços que atuam na estrutura), quanto ao ataque de organismos xilófagos.

A segunda espécie mais comercializada foi a Andiroba, constatada em $75 \%$ das empresas. A madeira de Andiroba, segundo o IPT (2015), quando exposta em condições adversas, é considerada de resistência moderada ao ataque de organismos. Na construção é utilizada como assoalhos, mobília, acabamento e ornamentação de interiores.

Além de apresentar essas características, essas duas espécies mais comercializadas apresentam também boa aparência e trabalhabilidade e são indicadas para aplicações internas em construção civil, como vigas, caibros, ripas, rodapés, molduras, cordões, venezianas, tábuas para assoalhos etc.

Outras espécies como Muiracatiara, Guajará, Pinus e Eucalyptus são comercializadas por 50\% das empresas. As espécies Muiracatiara e Guajará são empregadas para fabricação de esquadrias (portas e janelas). Vale ressaltar também que 50\% das empresas comercializam madeira mista, que se refere a espécies não definidas, de baixo valor comercial, misturadas em um mesmo lote usados comumente como material de suporte para formas de concreto não abrir na concretagem, abrigos de material ou tapumes.

As espécies Pinus e Eucalyptus (florestas plantadas) estão sendo incorporadas a construção civil pouco a pouco para substituir espécies de florestas tropicais, o que provavelmente seja o motivo de que ainda apenas $50 \%$ das madeireiras as comercializarem.

A madeira de Louro, da mesma forma da Muiracatiara e Guajará, é uma espécie utilizada para esquadrias devido a sua boa aparência decorativa e trabalhabilidade, mas foi observada em apenas uma empresa provavelmente devido a maior aceitação e procura do mercado por outras espécies.

A tabela 6 a seguir apresenta as espécies mais solicitadas pelos clientes e, consequentemente, as mais comercializadas pelas empresas.

Tabela 6: Espécies mais comercializadas pelas madeireiras.

\begin{tabular}{llllll}
\hline ITENS CITADOS & $\%$ & M1 & M2 & M3 & M4 \\
\hline Maçaranduba & 75 & $\mathrm{X}$ & - & $\mathrm{X}$ & $\mathrm{X}$ \\
Muiracatiara & 25 & - & - & $\mathrm{X}$ & - \\
Guajará & 25 & - & $\mathrm{X}$ & - & - \\
\hline
\end{tabular}

Sendo: M1, M2, M3 e M4, as madeireiras entrevistadas.

FONTE: Autoria Própria, (2016).

A Maçaranduba foi relatada como preferida dos clientes em $75 \%$ das empresas. Já a Guajará e a Muiracatiara são comercializadas em $25 \%$ delas, onde são usados para a produção de esquadrias devido a sua boa aparência e trabalhabilidade. Entre as duas espécies utilizadas para esquadrias, a Muiracatiara é a mais solicitada pelos clientes pois além de ter uma alta resistência, ela também possui boa aparência.

A tabela 7 apresenta a origem (estado) da madeira comercializada na região de Mossoró. 
Tabela 7: Origem (Estado) da madeira comercializada.

\begin{tabular}{llllll}
\hline ITENS CITADOS & $\%$ & M1 & M2 & M3 & M4 \\
\hline Pará & 100 & $\mathrm{X}$ & $\mathrm{X}$ & $\mathrm{X}$ & $\mathrm{X}$ \\
Minas Gerais & 25 & - & - & - & $\mathrm{X}$ \\
Paraná & 25 & - & - & - & $\mathrm{X}$ \\
\hline
\end{tabular}

Sendo: M1, M2, M3 e M4, as madeireiras entrevistadas

FONTE: Autoria Própria, (2016).

Todas as empresas comercializam madeiras oriundas do Pará. Essa predominância do local de origem pode ser justificada pela preferência do mercado pelas madeiras tropicais (Maçaranduba e Muiracatiara) nativas deste estado. Foi observado que apenas uma madeireira comercializa madeiras de Minas Gerais e Paraná. Esta madeireira em específico comercializa madeira roliça de Eucalyptus tratado e tábuas de Pinus. Estes produtos são comprados de regiões onde há o plantio destas espécies: Minas Gerais e Paraná, respectivamente.

Os rejeitos da madeira gerado pelas madeireiras são comercializados pela maioria dessas empresas para serem utilizados como pó em granjas ou como lenha para as indústrias de cerâmicas, indústria da poupa de fruta e restaurantes que utilizam forno a lenha. Uma das empresas comercializa os materiais da madeira da mesma forma que a recebe, não passando pelos processos de corte e adequação aos tamanhos do projeto, com isso não há rejeitos gerados na comercialização nesse caso.

\section{CONCLUSÕES}

Com base nos dados levantados com as empresas que comercializam madeira e com as empresas construtoras no município de Mossoró-RN, as seguintes considerações podem ser feitas:

- A madeira como item permanente é mais utilizado em coberturas, enquanto como item temporário é mais comum em formas para concretagem.

- A espécie mais comercializada e usada é a Maçaranduba.

- As empresas da construção civil de Mossoró trabalham com um fornecedor de madeira em comum.

- Os rejeitos de madeira das empresas construtoras, assim como todo os rejeitos de obra, são coletados por empresas especializadas.

- A madeira serrada em geral é o principal produto disponível no comércio local, sendo que sua origem é de outros estados que não fazem parte da região da caatinga.

- Os rejeitos de madeira das madeireiras são comercializados em forma de pó ou lenha.

\section{BIBLIOGRAFIA}

[1] ARAÚJO, R. T., “Alternativas sustentáveis do uso da madeira na construção civil”, Especialize. n.4, p. 1$15,2012$.

[2] FEITOZA, R., TRABALHO DE SISTEMAS, 2015. Disponível em:

<www.ebah.com.br/content/AbAAAewEgAG/trabalho-sistemas>. Acessado em: 05 de Janeiro de 2016.

[3] GESUALDO, F. A. R. ESTRUTURAS DE MADEIRA., Disponível em:

<http://www.feciv.ufu.br/sites/feciv.ufu.br/files/Anexos/Bookpage/Notas_de_Aula_Madeiras.pdf> 2003. Acessado em Janeiro de 2016.

[4] IBGE. Instituto Brasileiro de Geografia e Estatística. Estimativas da população residente no Brasil e Unidades da Federação com data de Referência em $1^{o}$ de Julho de 2015. 2015. Disponível em < ftp://ftp.ibge.gov.br/Estimativas_de_Populacao/Estimativas_2015/estimativa_dou_2015_20150915.pdf>. Acessado em: Janeiro de 2016.

[5] IPT. Instituto de Pesquisas Tecnológicas. Catálogo de madeiras brasileiras para a construção civil. São Paulo, IPT. 2013.

[6] KRAMBECK, T. I., Revisão de sistema construtivo em madeira de floresta plantada para habitação popular, Dissertação de M.Sc., Universidade Federal de Santa Catarina - UFSC. Florianópolis, 2006.

[7] ZENID, G. J., ROMAGNANO, L. F. T., NAHUZ, M. A. R., et al., Madeira: uso sustentável na construção civil. São Paulo, IPT/SCTDE, 2009. 